\title{
Sport officiating recruitment, development, and retention: A call to action
}

\author{
Lori A. Livingston 1,*, Susan L. Forbes ${ }^{1}$, Nicky Pearson², Tony Camacho ${ }^{2}$, Nick Wattie ${ }^{1} \&$ Paul Varian ${ }^{3}$ \\ 1 Faculty of Health Sciences, University of Ontario Institute of Technology, Oshawa, Ontario, Canada \\ 2 Ontario Soccer, Vaughan, Ontario, Canada \\ 3 Capitis Consulting, Burlington, Ontario, Canada \\ * Corresponding author: Lori A. Livingston, University of Ontario Institute of Technology, 2000 Simcoe Street North Oshawa, ON, L1H 7K4 \\ Canada, Tel: +011905 7218668 \\ Email: lori.livingston@uoit.ca
}

\section{REPORT}

\section{Article History:}

Submitted $4^{\text {th }}$ June 2017

Accepted $9^{\text {th }}$ December 2017

Published $18^{\text {th }}$ December 2017

\section{Handling Editor:}

Ernst-Joachim Hossner, University of

Bern, Switzerland

Editor-in-Chief:

Martin Kopp

University of Innsbruck, Austria

\section{ABSTRACT}

The purpose of this article is to report on the outcome of a two-day consensus-building exercise amongst sport scientists and sport practitioners interested in the recruitment, development, and retention of sport officials. Twenty participants including volunteers and paid employees affiliated with nine Ontario-based sport organizations, university researchers, and provincial government policy makers participated. A call to action regarding sport officiating and, more specifically, "What do we know?", "What don't we know?", and "Where does the research need to go from here?" is presented. A willingness to consider and embrace these ideas is critical in moving sport officiating from being an understudied and undervalued segment of the sport system to receiving the attention and respect it deserves going forward.

Keywords:

perceived organizational support - long-term officiating development - sport governance

Reviewers:

Reviewer 1: Ralf Brand,

University of Potsdam, Germany

Reviewer 2: Otto Kolbinger, Technical

University of Munich, Germany

Citation:

Livingston, L. A., Forbes, S. L., Pearson, N., Camacho, T., Wattie, N., \& Varian, P. (2017). Sport officiating recruitment, development, and retention: A call to action. Current Issues in Sport Science, 2:011. doi: 10.15203/CISS_2017.011

\section{Introduction}

With reports of annual attrition rates in officiating in excess of $20 \%$ for various sports around the world (Cuskelly \& Hoye, 2013; Forbes \& Livingston, 2013; Gencay, 2009; Hancock, Dawson, \& Auger, 2015; Parsons \& Balmer, 2015; VanYperen, 1998), there is more than ample evidence that officiating dropout is a persistent, pervasive, and global problem. Given this observation, it is quite ironic that efforts to understand this phenomenon have remained relatively uninformed by a rapidly expanding body of sport science literature. Indeed, the sport science literature as we know it is almost exclusively focused on athletes and coaches - but not officials - in sport (Forbes \& Livingston, 2013). The relative dearth of information on the sport officiating experience is problematic, but so too is the limited scope of the investigations to date. For example, the overwhelming majority of early studies focused on the purported relationship between stress and the intention to leave among elite, adult-aged male officials in mainstream sport (Goldsmith \&Williams, 1992; Rainey, 1995; Rainey \& Hardy, 1999; Taylor, Daniel, Leith, \& Burke, 1990). This is understandable given the frequency with which the popular media brings to 
our attention very public displays of coaches and spectators hurling verbal abuse at officials. In fact, however, since the early 1990s these investigations have consistently demonstrated that the stress experienced by officials explains little about their drop out (Cuskelly \& Hoye, 2013; Gencay, 2009). Until fairly recently, moreover, few sport scientists were willing to examine officiating attrition at other levels (i.e., grass roots or entry level) or as a product of other factors (Forbes \& Livingston, 2013; Kellett \& Warner, 2011) within organized sport systems.

Fortunately, throughout the past decade, there has been a growing interest in sport officials and therefore some progress made in gaining a broader understanding of their experiences (Bernal, Nix, \& Boatwright, 2012; Cunningham, Simmons, Mascarenhas, \& Redhead, 2014; Guillén \& Feltz, 2011; Johansen \& Haugen, 2013; Kellett \& Warner, 2011; Kruger, Strydom, Ellis, \& Ekmekci, 2012; Schweizer, Plessner, \& Brand, 2013; Souchon et al., 2013). This trend is readily apparent in Canada where numerous investigations (Auger, Fortier, Thibault, \& Gravelle, 2010; Betts, Forbes, \& Livingston, 2007; Dorsch \& Paskevich, 2007; Forbes \& Livingston, 2013; Hancock, Dawson, et al., 2015; Livingston \& Forbes, 2007, 2016, 2017a, 2017b; Philippe, Vallerand, Andrianarisoa, \& Brunel, 2009; Ste-Marie, 1999) are now contributing to an expanding body of literature on sport officiating, as well as an evolving understanding of why individuals enter into, remain committed, and leave from the amateur officiating ranks (Auger et al., 2010; Betts et al., 2007; Hancock, Dawson, et al., 2015; Livingston \& Forbes, 2007, $2016,2017 \mathrm{a}, 2017 \mathrm{~b})$. These studies provide evidence that the experiences, and therefore the developmental pathways for officials, are affected by a number of factors (or constraints as per Newell's, 1986, constraints model) including those that relate to the individual (e.g., years of experience in the role; gender), the task (e.g., the split second decision making required in an invasion game such as lacrosse versus judging a gymnastics routine against an ideal standard), and the environment (e.g., urban vs rural settings, varying levels of organizational support) in which they perform. A holistic approach aimed at understanding the challenges of recruiting, developing, and retaining amateur sport officials is clearly needed, as is a mechanism via which the resulting knowledge can be translated into action within existing sport systems (Engebretsen et al., 2014). In order to do this effectively, an integrated approach will be required; that is, one which combines the knowledge of the sport science community with the expertise and experiences of the administrators responsible for developing and launching organized sport programs.

The Canadian Sport for Life Long-Term Athlete Development (LTAD) project (www.sportforlife.ca) has defined a practitionerdriven and age-structured approach to attracting youth to and increasing their participation rates within sport, with the purpose of achieving performance excellence and ensuring their long-term participation, health and well-being (Lloyd et al., 2015; Norris, 2010). Succinctly put, the LTAD framework covers the full life span from birth to one's elder years, beginning with engagement in physical activity and the development of fundamental motor skills in fun, age-appropriate training environments. Thereafter, being active for life may take different forms, depending upon whether an individual chooses a competitive or recreational participation pathway. It provides an excellent example of a framework that may be adapted for use with youth interested in becoming sport officials, as well as those who are already active in the role. However, the evolution of an analogous system-wide "Long-Term Officiating Development" (LTOD) model has yet to materialize in Canada.

To this end, on January 11-12, 2017, a Multisport Officiating "Think Tank" meeting was held at Ontario Soccer's headquarters in Vaughan, Ontario, Canada. The primary objective was to discuss transformative and sustainable approaches to the recruitment, development, and retention of amateur sports officials (e.g., referees, umpires, judges and others). Recognizing that the gathering presented a rare opportunity to bring together sport science researchers with those responsible for designing, planning, implementing, and evaluating sport officiating initiatives (e.g., LTOD programs), the event had three explicit goals. The first was to provide those present with an up-to-date understanding of the sport officiating literature with a focus on what we know about why individuals enter into the role, what will retain them in the role, and what factors contribute to their decisions to leave. Strategies, as outlined in the literature, to increase participation in officiating and positive development in the avocation were also presented. The second was to provide the participants with information on existing organizational structures within amateur sport organizations in Canada. These were then contrasted and compared to one provincial sport organization's (PSO) nascent efforts to design, plan, implement, and evaluate a soon to be launched LTOD program for its officials. Finally, and perhaps most importantly, the "Think Tank" led to this call to action on officiating recruitment, development, and retention based on the following question: Given the sport science literature and our collective experiences in organized sport, what do we know, what don't we know, and where does the sport officiating research agenda need to go from here?

\section{Methods}

Twenty participants, including volunteers and paid employees affiliated with nine PSOs (i.e., Athletics Ontario, Baseball Ontario, Basketball Ontario, Ontario Rugby Union, Ontario Soccer, Ontario Volleyball Association, Softball Ontario, Ontario Colleges Athletics Association, and Ontario University Athletics), a group of university researchers, a sport strategic planning consultant, and representatives from the Ontario Provincial Ministry of Culture, Tourism, and Sport participated. It is worth noting that the majority of the participants were either still active or had extensive experience as provincially-, nationally-, and internationally-ranked officials in their respective sports, as well as direct or indirect oversight or input into officiating development programs. 
Four 40-minute long keynote presentations on sport officiating were delivered by the authors of this paper over the course of the two-day event: (a) recruitment, retention, and attrition research; (b) psychosocial support for developing officials; (c) organizational governance and funding structures; and, (d) LTOD programs. Each presentation was designed to introduce the participants to the current sport science literature and examples of current practices in each topic area. Following each presentation, there was a one hour long facilitated discussion guided by the following three questions: (a) "What do we know about this topic?"; (b) "What don't we know about this topic?"; and, (c) "Where does the research need to go from here?" Three designated note takers captured each discussion in detail. It is from these discussion notes, as well as a priori and post hoc examinations of the sport science literature, that the authors distilled and agreed to the content of the following call to action.

\section{Recruitment, retention, and attrition research}

\section{What do we know?}

1. Sport officials (e.g., referees, judges, umpires, stewards, commissaires) are frequently viewed as independent contractors rather than key participants who play a vital role in building capacity within organizations. This contributes to an "us versus them" mentality and an expectation of perfection in return for pay regardless of the age or experience level of the official in question (Anshel, Kang, \& Jubenville, 2013; Kruger et al., 2012).

2. Drop out (or attrition) from the officiating ranks is not unique to any given sport. It is a pervasive, persistent, and global problem (Cuskelly \& Hoye, 2013; Gencay, 2009; Hancock, Dawson, et al., 2015; Livingston \& Forbes, 2013; Parsons \& Balmer, 2015; VanYperen, 1998).

3. The majority of the early officiating studies were negatively and narrowly focused (Kellett \&Warner, 2011; Warner, Tingle, \& Kellett, 2013); that is, they focused on why individuals leave rather than why they enter into, stay, or thrive in the role. The limited samples of participants in these studies, moreover, were largely male, adult-aged, and participating at the elite level (e.g., professional, semi-professional) in mainstream sports (e.g., soccer, basketball, ice hockey) (Forbes \& Livingston, 2013). Consequently, there has been very little investigation into the entry-level or grass roots officiating experience (Livingston \& Forbes, 2016; Wicker \& Frick, 2016).

4. Young, inexperienced officials are negatively affected by the threat of verbal and physical abuse and it is the most frequently cited reason for their departure from officiating (Folkesson, Nyberg, Archer, \& Norlander, 2002; Kruger et al., 2012; Livingston \& Forbes, 2007).

5. Experienced officials, in contrast, tend to normalize abuse and are more likely to cite career or family demands as the primary reason for their departure (Burke, Joyner, Pim, \& Czech, 2000; Gencay, 2009; Goldsmith \& Williams, 1992; Johansen \& Haugen, 2013; Kellett \& Shilbury, 2007; Parsons \& Balmer, 2015; Titlebaum, Haberlin, \& Titlebaum, 2009).

6. All officials, regardless of age or years of experience, cite lack of mentorship and supervision, poor quality training, and a lack of recognition for their efforts as contributors to their decision to drop out (Auger et al., 2010; Livingston \& Forbes, 2007, 2013).

7. Attrition from the officiating ranks is costly. It represents a loss of investment in officials that have been trained as well as a loss of their expertise and talent. It also requires additional human, financial, and capital investments to recruit and train new officials to replace those who have left (Cuskelly \& Hoye, 2013; VanYperen, 1998).

8. Approximately four out of every five active sport officials have participated in the sport they officiate (Livingston \& Forbes, 2016). The most frequently cited reason for entering into officiating is enjoyment or love for the sport (Betts et al., 2007; Hancock, Dawson, et al., 2015; Johansen, 2015; VanYperen, 1998; Wolfson \& Neave, 2007). Officials are also frequently encouraged by significant others (e.g., teachers, coaches, or other role models) to enter into the role. They value the sport identity and the social connections they gain through their participation (Bernal et al., 2012; Cuskelly, 2004; Hancock, Dawson, et al., 2015; Johansen, 2015; Kellett \& Shilbury, 2007).

9. Financial remuneration may attract some, especially younger officials, to enter officiating, but it does not influence retention (Betts et al., 2007; Hancock, Dawson, et al., 2015; Livingston \& Forbes, 2016).

10. Both males and females are intrinsically motivated to officiate, gaining both a sense of enjoyment and excitement from their participation. For males, their sense of excitement and enjoyment remains relatively stable while that of females declines over time (Kim \& Hong, 2016; Livingston \& Forbes, 2016; Schaeperkoetter, 2017; Tingle, Warner, \& Sartore-Baldwin, 2014).

11. Perceived organizational support (POS) is an important contributor to one's intention to remain active as an official. It is an important contributor to the development of selfefficacy and job satisfaction in an officiating role (Kerwin, Jordan, \& Turner, 2015; Kim \& Andrew, 2015).

12. Officials will remain active within their sport if they perceive the rewards associated with their participation are greater than the costs they incur (Bang, Ross, \& Reio, Jr., 2012; Titlebaum et al., 2009).

\section{What don't we know?}

1. Recognize officials as key stakeholders in existing sport systems. Develop a mechanism as well as an understanding of how they may best be integrated into administrativeand governance-related roles at all levels (e.g., club, district, regional, national) within amateur sport systems. 
2. Employ new frameworks of inquiry (i.e., positive, optimistic, theoretical) and methodological approaches (e.g., large sample size, new statistical approaches) when studying sport officials (Anshel et al., 2013; Forbes \& Livingston, 2013; Kellett \& Shilbury, 2007).

3. Investigate and understand how the officiating experience changes over time (e.g., from grass-roots to competitive levels of competition) and how it differs between males and females (Folkesson et al., 2002; Kim \& Hong, 2016; Livingston \& Forbes, 2016; Pizzera, 2015; Schaeperkoetter, 2017; Slack et al., 2013; Tingle et al., 2014).

4. Develop evidence-informed LTOD models as a natural and complimentary extension to existing LTAD frameworks.

\section{Psychosocial support for developing officials}

\section{What do we know?}

1. Sport officials, like athletes, need to invest time and effort to develop and acquire domain-specific officiating skills (Plessner \& MacMahon, 2013).

2. Like athletes, the development of sport officials relies on optimizing the developmental environment relative to individual's characteristics and needs, and the sport-specific officiating demands (e.g., reactors, monitors, interactors, knowledge, game management, communication, physical demands) (Plessner \& MacMahon, 2013).

3. Self-efficacy, a person's belief that he or she can complete some behaviour or task successfully (Bandura, 1977, 1986), is critical to success in officiating.

4. Experience, physical and mental preparation, and comfort with the task at hand will add to or enhance an official's selfefficacy (Myers, Feltz, Guillén, \& Dithurbide, 2012).

5. Self-efficacy can have an insulating effect; that is, it can protect an individual from stressors or adversity, and can help to regulate behaviour and motivation (Lirgg, Feltz, \& Merrie, 2013).

6. Perceived organizational support (POS) is an important contributor to sport officials' self-efficacy (Guillén \& Feltz, 2011).

7. A high level of self-efficacy for an official may improve his or her overall performance and lead to a greater commitment to the role. It may also contribute to the speed and accuracy with which decisions are rendered, lower stress levels, and contribute to greater satisfaction for others (e.g., coaches, athletes, spectators) (Guillén \& Feltz, 2011; Myers et al., 2012).

8. Officials are often significantly constrained in the number of training opportunities and hours they have outside of games/competitions, which likely influences their development (Plessner \& MacMahon, 2013).

9. Self-regulation skills, which reflect the degree to which individuals metacognitively, motivationally, and behaviourally contribute to their own learning, have been shown to distinguish those of different ability levels (Toering, Elferink-Gemser, Jordet, \& Visscher, 2009; Zimmerman, 2008). For example, they may help developing officials optimize the time spent on learning by improving their ability to prioritize what has to be learned and how to do it (e.g., the use of training logs and homework tasks).

\section{What don't we know?}

1. How might we identify the critical psychological characteristics required in the early stages of recruitment to become officials in sport? What abilities and characteristics (or strengths) would best predict their short- and long-term success?

2. Given that many officials begin as sport participants (Livingston \& Forbes, 2016), to what extent might participating in a sport contribute to success as an official in the same sport (i.e., talent transfer) (Plessner \& MacMahon, 2013)?

3. What are the developmental histories of successful officials (e.g., early developmental family and community environments, sport histories, officiating histories)? To what extent might an individual's developmental history contribute to his or her development as a sport official?

4. Is there value in discriminating between sport-specific and non-sport specific psychological skillsets for the purposes of training?

5. How may we create an environment that best matches individual needs to the different officiating demands of a given sport (Plessner \& MacMahon, 2013)? What environments promote retention, personal development, and skill development? What are the important skills to develop?

6. To what extent do social support and/or mentoring contribute to the development of self-efficacy within a sport official?

7. Are there important parallels between the normalization of emotional abuse of athletes (Stirling \& Kerr, 2015) and the normalization of abuse of officials (Dorsch \& Paskevich, 2007)? What interactions exist between emotional abuse, POS, healthy development, retention, and attrition?

\section{Where does the research need to go from here?}

1. Identify the critical psychological characteristics (e.g., selfefficacy) required in officiating and how they develop over time in talented high performing officials.

2. Identify the developmental histories of officials at different levels, including sport participation and officiating histories, training histories (e.g., practice histories), and characteristics of developmental environments.

3. Understand the constraints on officials' development given unique sport-specific officiating demands.

4. Measure the effectiveness of organizational policy changes and/or LTOD programming for individuals by measuring 
changes in self-efficacy, retention and attrition, and skill development over time.

\section{Organizational governance and funding structures}

\section{What do we know?}

1. Officials, and the roles they fulfill, are an essential part of organized sport and competition at all levels of the sport system (Hancock, Rix-Lièvre, \& Côté, 2015; Schweizer et al., 2013).

2. Via explicit exclusion of officials from organizational governance and funding structures, sport organizations (i.e., local, regional, provincial, and national) promote a culture of disrespect for officials (Auger et al., 2010; Betts et al., 2007; Forbes \& Livingston, 2013; Kellett \& Warner, 2011; Warner, Tingle, \& Kellett, 2012).

3. There is a great deal of time spent assigning officials to support athletic competitions. In contrast, there is often little effort or time invested in their development (Betts et al., 2007; Forbes \& Livingston, 2013; Livingston \& Forbes, 2007).

4. Until recently, officials were not typically found in organizational vision statements, strategic plans, budgets, or developmental programs (Government of Ontario, 2016; Sam, Andrew, \& Gee, 2017).

5. There is considerable variance in officiating programming across organizations and between different levels (e.g., local, district, regional, national) of amateur sport systems (Sam et al., 2017).

6. Officiating experiences assist in the development of life (leadership) skills (Tingle et al., 2014).

What don't we know?

1. Why have officials been more often than not excluded rather than included in sport organizations? What factors have contributed to this marginalization over time?

2. How might sport officials best be integrated into existing sport systems? Will financial incentives (e.g., change in sport funding models) be needed in order to effect such integration?

3. Even if incentives are made available, given the longstanding structures and practices present within amateur sport systems, how long will it take for officials to become recognized as an essential human resource within sport? What will it take for officials to be seen on par with their coaching counterparts?

4. How does involvement as a sport official explicitly contribute to the development of life skills?
Where does the research need to go from here?

1. Develop globally accepted LTOD frameworks which may be easily adapted and thereafter implemented by sport organizations at all levels. Education is global; implementation is local.

2. Examine existing sport governance structures and determine ways to establish clearer accountability in the system for officials' development. For example, who should take the lead - the national sport organization or the provincial-territorial organization, or both?

3. Develop diffuse sport leadership and funding models (e.g., via organizational strategic plans, governance structures) across all sports, ones which acknowledge and incorporate officials as key players in sport organizations.

4. Research-related centres of excellence in officiating development need to be established. Such centres would focus on all aspects of officials' development, as well as act as advocates for the recognition of officials as an essential part of the sporting infrastructure.

\section{Long-term officiating development programs}

\section{What do we know?}

1. The development, planning, implementation, and evaluation of LTOD programs will require resources (e.g., expertise, time, and facilities) and a commitment from sport administrators (Lloyd et al., 2015; Norris, 2010). "Champions" will need to be identified to lead the effort.

2. LTODs will provide a vehicle via which officiating administrations may articulate objective and well-defined performance standards and expectations for differing levels within their sport. They will also identify objective criteria via which game assignments, promotions, and recognitions will be achieved, replacing less well defined and problematic practices (e.g., favouritism in assigning) from the past (Betts et al., 2007; Forbes \& Livingston, 2013; Livingston \& Forbes, 2007).

3. LTODs will necessarily need to be incentivized. Such incentives need to be transparent and readily apparent to practicing officials (Bang et al., 2012; Kerwin et al., 2015; Kim \& Andrew, 2015). Even with these incentives in place, some attrition from the ranks is likely to occur.

4. Following LTOD program implementation, ongoing evaluation will be critical to determine if the desired end goals (e.g., increase in both the quantity and quality of officials) are being achieved (Parent \& Harvey, 2017).

5. "One size" does not and will not fit all. Sport specific LTODs will be required. 


\section{What don't we know?}

1. For a given sport, what does an effective LTOD program look like? What elements should be included? To what extent will a sport-specific LTOD align with or reflect elements of the same sport's existing LTAD framework? Are there opportunities to align or find efficiencies between LTADs and LTODs within any given sport or between sports?

2. Is there an opportunity to link participation within the system as an athlete, as defined by an LTAD, into participation as an official, as defined by an LTOD?

3. For maximum uptake and effectiveness, who should take the lead on developing LTODs? Should LTODs be championed from the bottom up or the top down, or both, within existing sport systems?

4. How may we effectively implement LTOD programs in predominantly volunteer driven organizations?

5. How effective will LTOD programs be in reducing officiating attrition rates, or in other words, increasing officiating retention? Will they prove to be more effective in improving participation numbers in certain age or experience groups than in others?

6. How effective will LTOD programs be in improving the quality of the officiating pool? Will they assist with talent identification?

7. Will higher quality officiating performances contribute to the positive development of athletes and therefore, higher quality athletic performances?

Where does the research need to go from here?

1. Design, plan, implement, and evaluate sport-specific LTOD programs.

2. Determine if existing LTAD philosophies and/or frameworks may contribute to the development of LTODs.

3. Examine opportunities to directly link LTAD frameworks to LTOD frameworks within or across sports; that is, examine how individuals may transit from being an athlete to being an official.

4. Explore the use of technology and/or technology-based programming as a vehicle in officiating education, mentorship, and communication.

\section{Discussion}

Over the past decade, the sport science community, in Canada and beyond, has started to take more interest in the study of sport officials (Auger et al., 2010; Bernal et al., 2012; Cunningham et al., 2014; Forbes \& Livingston, 2013; Gencay, 2009; Guillén \& Feltz, 2011; Hancock, Rix-Lièvre, et al., 2015; Johansen \& Haugen, 2013; Kellett \& Warner, 2011; Kim \& Hong, 2016; Kruger et al., 2012; Livingston \& Forbes, 2007, 2016, 2017a, 2017b; Philippe et al., 2009; Schaeperkoetter, 2017; Schweizer et al., 2013; Souchon et al., 2013). This has led to an expanding body of literature on sport officiating and, to some extent, an improved understanding as to why individuals enter into, remain committed, and leave the amateur officiating ranks. However, there is still much more to be done as is demonstrated by the content of this document. From our perspective, sport science researchers need to continue to problematize and study the issues as they relate to the recruitment, development, and retention of sport officials. To do so is important as it would send a strong signal to the global sport community that officials are a valued part of the sport system and that the continued marginalization of this important human resource cohort is no longer acceptable.

The significance of developing a critical mass of scholarship related to sports officials and the tasks they undertake should not be underestimated. A growing body of scholarship would provide an evidence-informed basis upon which sport organizations and their members (i.e., those who govern, fund, administer, organize, coach, and play) may begin to shift the dialogue and culture of sport from one of disrespect to one of respect for sport officials. Moreover, with a strong sport science base, the same organizations will be better situated to advocate for and develop sport- and developmentally-specific LTOD programs from the grassroots to the elite level for their officials. Success in these regards will only be realized, however, if sport scientists are willing to work with sport stakeholders and vice versa. Currently there are few officiating champions and leaders in either of these domains and that needs to change.

We were encouraged by the commitment of the "Think Tank" participants and the dialogue that arose over the course of the two-day event. The dialogue was passionate, productive, and provocative. We also recognize that this call to action may not reflect the officiating experiences of others in Canada or around the world, be they sport science or real-world sportrelated. In addition, we know that this call to action does not address the full expanse of existing literature on sport officiating (e.g., physiological demands, decision making, cognitive demands, etc.). Nonetheless, we believe that there are some unique and forward-thinking insights contained herein. Moreover, we strongly believe that a willingness to consider and embrace these ideas regarding the recruitment, development, and retention of sport officials will be critical in moving the arbiters of sport from being an understudied and undervalued segment of the global sport system to receiving the attention and respect they deserve going forward.

\section{Competing Interests}

The authors have declared that no competing interests exist.

\section{Data Availability Statement}

All relevant data are within the paper. 


\section{References}

Anshel, M. H., Kang, M., \& Jubenville, C. (2013). Sources of acute stress scale for sports officials: Rasch calibration. Psychology of Sport and Exercise, 14, 362-370.

Auger, D., Fortier, J., Thibault, A., \& Gravelle, F. (2010). Characteristics and motivations of sports officials in the province of Québec. International Journal of Sport Management, Recreation, \& Tourism, 5, 29-50.

Bandura, A. (1977). Self-efficacy: Toward a unifying theory of behavioral change. Psychological Review, 84, 191-215.

Bandura, A. (1986). Social foundations of thought and action. Englewood Cliffs: Prentice-Hall.

Bang, H., Ross, S., \& Reio, Jr., T. G. (2012). From motivation to organizational commitment of volunteers in non-profit sport organizations. Journal of Management Development, 32, 96-112.

Barney, J. B. (1991). Firm resources and sustained competitive advantage. Journal of Management, 17, 99-120.

Bernal, J. C., Nix, C., \& Boatwright, D. (2012). Sport officials' longevity: Motivation and passion for the sport. International Journal of Sport Management, Recreation, \& Tourism, 10, 28-39.

Betts, M. J., Forbes, S. L., \& Livingston, L. A. (2007). Factors contributing to the attrition of Canadian amateur ice hockey officials: The experiences of referees and linesmen in Atlantic Canada. Avante, 11, 15-22.

Burke, K. L., Joyner, A. B., Pim, A., \& Czech, D. R. (2000). An exploratory investigation of the perceptions of anxiety among basketball officials before, during and after the contest. Journal of Sport Behavior, 23, 11-19.

Cunningham, I., Simmons, P., Mascarenhas, D., \& Redhead, S. (2014). Skilled interaction: Concepts of communication and player management in the development of sport officials. International Journal of Sport Communication, 7 , 166-187.

Cuskelly, G. (2004). Volunteer retention in community sport organizations. European Sport Management Quarterly, 4, 59-76.

Cuskelly, G., \& Hoye, R. (2013). Sports officials' intention to continue. Sport Management Review, 16, 451-464.

Dorsch, K. D., \& Paskevich, D. M. (2007). Stressful experiences among six certification levels of ice hockey officials. Psychology of Sport and Exercise, 8, 585-593.

Engebretsen, L., Bahr, R., Cook, J. L., Derman, W., Emery, C. A., Finch, C. F., Meeuwisse, W. H., Schwellnus, M., \& Steffen, K. (2014). The IOC Centres of Excellence bring prevention to sports medicine. British Journal of Sports Medicine, 48, 1270-1275.

Folkesson, P., Nyberg, C., Archer, T., \& Norlander, T. (2002). Soccer referees' experience of threat and aggression: Effects of age, experience, and life orientation on outcome of coping strategy. Aggressive Behavior, 28, 317-327.
Forbes, S. L., \& Livingston, L. A. (2013). Changing the call: Rethinking attrition and retention in the ice hockey officiating ranks. Sport in Society, 16, 295-309.

Gencay, S. (2009). Magnitude of psychological stress reported by soccer referees. Social Behavior and Personality, 37, 865868.

Goldsmith, P. A., \& Williams, J. M. (1992). Perceived stressors for football and volleyball officials from three rating levels. Journal of Sport Behavior, 15, 106-118.

Government of Ontario (2016). GameOn - The Ontario Goverenment's Sport Plan. Toronto, Ontario: Author.

Guillén, F., \& Feltz, D. L. (2011). A conceptual model of referee efficacy. Frontiers in Psychology, 2:25. doi: 10.3389/ fpsyg.2011.00025

Hancock, D. J., Dawson, D. J., \& Auger, D. (2015). Why ref? Understanding sport officials' motivations to begin, continue, and quit. Movement \& Sport Sciences, 87, 31-39.

Hancock, D. J., Rix-Lièvre, G., \& Côté, J. (2015). Citation network analysis of research on sport officials: A lack of interconnectivity. International Review of Sport \& Exercise Psychology, 8, 95-105.

Johansen, B. T. (2015). Reasons for officiating soccer: The role of passion-based motivations among Norwegian elite and non-elite referees. Movement \& Sport Sciences, 87, 23-30.

Johansen, B. T., \& Haugen, T. (2013). Anxiety level and decision making among Norwegian top-class soccer referees. International Journal of Sport and Exercise Psychology, 11, 215-226.

Kellett, P., \& Shilbury D. (2007). Umpire participation: Is abuse really the issue? Sport Management Review, 10, 209-229.

Kellett, P., \& Warner, S. (2011). Creating communities that lead to retention: The social worlds and communities of umpires. European Sport Management Quarterly, 11, 471494.

Kerwin, S., Jordan, J. S., \& Turner, B. A. (2015). Organizational justice and conflict: Do perceptions of fairness influence disagreement? Sport Management Review, 18, 384-395.

Kim, M. C., \& Hong, E. (2016). A red card for women: Female officials ostracized in South Korean football. Asian Journal of Women's Studies, 22, 114-130.

Kim, S., \& Andrew, D. P. S. (2015). Relationships between organizational justice and coaches' attitudinal outcomes in intercollegiate athletics. International Journal of Sports Science \& Coaching, 10, 305-326.

Kruger, A., Strydom, G., Ellis, S., \& Ekmekci, R. (2012). Stressors among South African soccer officials: A profile analysis. South African Journal for Research in Sport, Physical Education, and Recreation, 34, 53-62.

Lirgg, C. D., Feltz, D. L., \& Merrie, M. D. (2013). Self-efficacy of sports officials: A critical review of the literature. Journal of Sport Behavior, 39, 39-50.

Livingston, L. A., \& Forbes, S. L. (2007). Factors contributing to the attrition of Canadian amateur ice hockey officials: Survey results from an Ontario-based district hockey association. Avante, 11(1), 1-14. 
Livingston, L. A., \& Forbes, S. L. (2016). Factors contributing to the retention of Canadian amateur sport officials: Motivations, perceived organizational support, and resilience. International Journal of Sports Science \& Coaching, 11, 342-355.

Livingston, L. A., \& Forbes, S. L. (2017a). “Just bounce right back up and dust yourself off": Participation motivations, resilience, and perceived organizational support among amateur baseball umpires. Baseball Research Journal, 46(2), 91-101.

Livingston, L. A., \& Forbes, S. L. (2017b). Resilience, motivations for participation, and perceived organizational support amongst aesthetic sport officials. Journal of Sport Behavior, 40, 43-67.

Lloyd, R. S., Oliver, J. L., Faigenbaum, A. D., Howard, R., De Ste Croix, M. B., Williams, C. A., Best, T. M., Alvar, B. A., Micheli, L. J., Thomas, D. P., Hatfield, D. L., Cronin, J. B., \& Myer, G. D. (2015). Long-term athletic development - part 1: A pathway for all youth. Journal of Strength \& Conditioning Research, 29, 1439-1450.

Myers, N. D., Feltz, D. L., Guillén, F., \& Dithurbide, L. (2012). Development of, and initial validity evidence for, the referee self-efficacy scale: A multistudy report. Journal of Sport \& Exercise Psychology, 34, 737-765.

Newell, K. M. (1986). Constraints on the development of coordination. In M. G. Wade \& H. T. A. Whiting (Eds.), Motor development in children: Aspects of coordination and control (pp. 341-360). Amsterdam: Martinus Nijhoff.

Norris, S. R. (2010). Long-term athlete development in Canada: Attempting system change and multi-agency cooperation. Current Sports Medicine Reports, 9, 379-382.

Parent, M. M., \& Harvey, J. (2017). A partnership-based evaluation of a community-based youth sport and physical activity programme. Sport in Society, 20, 7-29.

Parsons, T., \& Balmer, A. (2015). You want the buzz of having done well in a game that wasn't easy: A sociological examination of the job commitment of English football referees. Movement \& Sport Sciences, 87, 41-52.

Philippe, F. L., Vallerand, R. J., Andrianarisoa, J., \& Brunel, P. (2009). Passion in referees: Examining their affective and cognitive experiences in sport situations. Journal of Sport \& Exercise Psychology, 31, 77-96.

Pizzera, A. (2015). The role of embodied cognition in sports officiating. Movement \& Sport Sciences, 87, 53-61.

Plessner, H., \& MacMahon, C. (2013). The sports official in research and practice. In D. Farrow, J. Baker, \& C. MacMahon (Eds.), Developing sport expertise: Researchers and coaches put theory into practice (pp. 172-192). New York: Routledge.

Qi, Y. S., \& Shi, Y. G. (2016). Using a 3D technology in the network distance teaching of "sport training". International Journal of Emerging Technologies in Learning, 11(5), 45-50.

Rainey, D. W. (1995). Sources of stress among baseball and softball umpires. Journal of Applied Sport Psychology, 7, 1-10.
Rainey, D. W., \& Hardy, L. (1999). Sources of stress, burnout and intention to terminate among rugby union referees. Journal of Sports Sciences, 17, 797-806.

Ratten, V. (2016). The dynamics of sport marketing: Suggestions for marketing intelligence and planning. Marketing Intelligence \& Planning, 34, 162-168.

Sam, M. P., Andrew, J. C., \& Gee, S. (2017). The modernisation of umpire development: Netball New Zealand's reforms and impacts. European Sport Management Quarterly. Published online October 10, 2017. doi: 10.1080/16184742.2017.1377272

Schaeperkoetter, C. C. (2017). Basketball officiating as a gendered arena: An autoethnography. Sport Management Review, 20, 128-141.

Schweizer, G., Plessner, H., \& Brand, R. (2013). Establishing standards for basketball elite referees' decisions. Journal of Applied Sport Psychology, 25, 370-375.

Slack, L. A., Maynard, I. W., Butt, J., \& Olusoga, P. (2013). Factors underpinning football officiating excellence: Perceptions of English Premier League officials. Journal of Applied Sport Psychology, 25, 298-315.

Souchon, N., Fontayne, P., Livingstone, A., Maio, G. R., Mellac, N., \& Genolini, C. (2013). External influences on referees' decisions in judo: The effects of coaches' exclamations during throw situations. Applied Sport Psychology, 25, 223233.

Ste-Marie, D. M. (1999). Expert-novice differences in gymnastic judging: An information-processing perspective. Applied Cognitive Psychology, 13, 269-281.

Stirling, A., \& Kerr, G. (2015). Safeguarding athletes from emotional abuse. In M. Lang \& M. Harthill (Eds.), Safeguarding, child protection and abuse in sport: International perspectives in research, policy and practice (pp. 143-152). London: Routledge.

Taylor, A. H., Daniel, J. V., Leith L, \& Burke, R. J. (1990). Perceived stress, psychological burnout and paths to turnover intentions among sports officials. Journal of Applied Sport Psychology, 2, 84-97.

Tingle, J., Warner, S., \& Sartore-Baldwin, L. (2014). The experience of former women officials and the impact on the sporting community. Sex Roles, 71, 7-20.

Titlebaum, P. J., Haberlin, N., \& Titlebaum, G. (2009). Recruitment and retention of sport officials. Recreational Sports Journal, 33, 102-108.

Toering, T. T., Elferink-Gemser, M. T., Jordet, G., \& Visscher, C. (2009). Self-regulation and performance level of elite and non-elite youth soccer players. Journal of Sports Sciences, 27, 1509-1517.

Truyens, J., De Bosscher, V., Sotiriadou, P., Heyndels, B., \& Westerbeek, H. (2016). A method to evaluate countries' organisational capacity: A four country comparison in athletics. Sport Management Review, 19, 279-292.

VanYperen, N.W. (1998). Predicting stay/leave behavior among volleyball referees. Sport Psychologist, 12, 427-439. 
Warner, S., Tingle, J. K., \& Kellett, P. (2012). An administrative mess: A case study from the officiating community. Sport Management Review, 15, 368-380.

Warner, S., Tingle, J. K., \& Kellett, P. (2013). Officiating attrition: The experiences of former referees via a sport development lens. Journal of Sport Management, 27, 316328.

Wicker, P., \& Frick, B. (2016). Recruitment and retention of referees in non-profit sport organizations: The trickledown effect of role models. Voluntas, 27, 1304-1322.

Wolfson, S., \& Neave, N. (2007). Coping under pressure: Cognitive strategies for maintaining confidence among soccer referees. Journal of Sport Behavior, 30, 232-248.

Zimmerman, B. J. (2008). Investigating self-regulation and motivation: Historical background, methodological developments, and future prospects. American Educational Research Journal, 45, 166-183. 